\title{
Electron impact fragmentation of thymine: partial ionization cross sections for positive fragments ${ }^{\star}$
}

\author{
Peter J.M. van der Burgt ${ }^{\mathrm{a}}$, Francis Mahon, Gerard Barrett, and Marcin L. Gradziel \\ Department of Experimental Physics, National University of Ireland Maynooth, Maynooth, Co. Kildare, Ireland
}

Received 8 November 2013 / Received in final form 2 April 2014

Published online 23 June 2014 - (C) EDP Sciences, Società Italiana di Fisica, Springer-Verlag 2014

\begin{abstract}
We have measured mass spectra for positive ions for low-energy electron impact on thymine using a reflectron time-of-flight mass spectrometer. Using computer controlled data acquisition, mass spectra have been acquired for electron impact energies up to $100 \mathrm{eV}$ in steps of $0.5 \mathrm{eV}$. Ion yield curves for most of the fragment ions have been determined by fitting groups of adjacent peaks in the mass spectra with sequences of normalized Gaussians. The ion yield curves have been normalized by comparing the sum of the ion yields to the average of calculated total ionization cross sections. Appearance energies have been determined. The nearly equal appearance energies of $83 \mathrm{u}$ and $55 \mathrm{u}$ observed in the present work strongly indicate that near threshold the $55 \mathrm{u}$ ion is formed directly by the breakage of two bonds in the ring, rather than from a successive loss of HNCO and CO from the parent ion. Likewise $54 \mathrm{u}$ is not formed by CO loss from $82 \mathrm{u}$. The appearance energies are in a number of cases consistent with the loss of one or more hydrogen atoms from a heavier fragment, but $70 \mathrm{u}$ is not formed by hydrogen loss from $71 \mathrm{u}$.
\end{abstract}

\section{Introduction}

In recent years many studies of electron collisions with molecules have focused on biomolecules such as the nucleobases in the gas phase (for reviews see [1-5]). The purpose of this article is to present new results for lowenergy electron impact to thymine in the gas phase leading to the formation of positively charged fragments. Several groups have already looked at mass spectra of thymine, but in this article we present ionization cross sections for most of the positively charged fragments. We have normalized the yield curves of the fragment ions by comparing the total ion yield to the total ionization cross section of thymine obtained from theoretical calculations. The aim of this article is to present these results, which provide new information about the appearance energies of the positive fragments, the fragmentation pathways initiated by electron impact, and the ionization cross sections for the production of these ions.

Thymine has been the focus of a number of collisions studies involving electron, photon and ion impact. Mass spectrometry following $20 \mathrm{eV}$ and $70 \mathrm{eV}$ electron impact on thymine, ${ }^{14} \mathrm{C} 2$-thymine and thymine- $\mathrm{d}_{3}-6$ - $\mathrm{d}$ has been performed by Rice et al. [6], Ulrich et al. [7], and

\footnotetext{
* Contribution to the Topical Issue "Electron and Positron Induced Processes", edited by Michael Brunger, Radu Campeanu, Masamitsu Hoshino, Oddur Ingólfsson, Paulo Limão-Vieira, Nigel Mason, Yasuyuki Nagashima and Hajime Tanuma.

a e-mail: peter.vanderburgt@nuim.ie
}

Imhoff et al. [8]. Their results will be compared with our results later in this paper.

Electron energy-loss spectroscopy has been used by Abouaf et al. [9] to study electronic and vibrational excitation of thymine molecules. Dal Cappello et al. [10,11] present theoretical and experimental triply differential cross sections for the ionization of thymine by $250 \mathrm{eV}$ electrons and positrons and compare these with first and second Born calculations.

Dissociative electron attachment (DEA) has been studied by Huels et al. [12], Denifl et al. [13,14] and Abouaf and Dunet [15]. The most comprehensive study [14] identifies 9 different reaction channels for the formation of different negative ions. DEA of partly deuterated thymine and methylated thymine [16-21] have shown that resonances observed in the yields of the negative fragment ions are associated with very specific bond breakages in the thymine molecule.

A comprehensive study of vibrational Feshbach resonances in DEA of thymine has been performed by Burrow et al. [22]. Other theoretical work includes a study of hydrogen loss via DEA [23], an $R$-matrix study of elastic and inelastic electron collisions with thymine [24], and the application of density functional theory to radical cations of thymine [25].

Jochims et al. [26] have used synchrotron radiation for photo-ion mass spectrometry of thymine in the $6-22 \mathrm{eV}$ photon energy range. Itälä et al. [27] have studied soft X-ray $(330 \mathrm{eV})$ induced fragmentation processes of thymine using a photoelectron-photoionphotoion coincidence technique. 
A variety of studies of ions colliding with thymine in the gas phase have been performed. Schlathölter and coworkers [28-32] have used time-of-flight mass spectrometry to study $\mathrm{C}^{q+}(q=1-6 ; 4 \mathrm{keV} / \mathrm{u})$ and $\mathrm{Xe}^{q+}(q=5-25$; $0.5 \mathrm{MeV}$ ) collisions with thymine. Tabet et al. [33] present results for $80 \mathrm{keV}$ proton impact with separation of direct ionization and electron capture.

Very recently there has been an increased interest in collisions of DNA base clusters and DNA bases embedded in clusters. Kim et al. [34] have determined ionization potentials of hydrated thymine under electron impact. Kim et al. [35] (different group) have studied UV photofragmentation of thymine clusters. Kagawa et al. [36] have studied fragmentation of hydrated thymine by UV laser pulses at $266 \mathrm{~nm}$. Schlathölter et al. [37] have applied coincidence time-of-flight spectrometry in collisions of $\mathrm{keV}$ ions with thymine clusters. Zappa et al. [38] have studied electron impact ionization of thymine clusters embedded in superfluid helium droplets.

The present paper focuses exclusively on collisions with isolated thymine molecules. In the following sections we discuss our experimental set-up, the data acquisition, and the methods used for analysis of the data. We then present the results, compare these with other research, in particular electron and photon impact mass spectrometry, and discuss possible reaction mechanisms.

\section{Experiment}

The experimental set-up consists of a small oven producing an effusive beam of thymine molecules, a pulsed electron beam, and a reflectron time-of-flight mass spectrometer. An overview of the experiment can be found in reference [39]. The pulsed valve used in reference [39] for the generation of clusters has been replaced by the oven.

The thymine beam is generated by resistively heating the oven containing thymine powder (from Sigma Aldrich, $99 \%$ purity) to a temperature of $180{ }^{\circ} \mathrm{C}(453 \mathrm{~K})$. The molecular beam effuses from a capillary $(0.5 \mathrm{~mm}$ diameter and $4.5 \mathrm{~mm}$ length), and passes through a skimmer (1.2 mm diameter) into the collision chamber, where the beam is crossed by the electron beam. The alignment of the oven, skimmer and electron gun is ensured by the mounting of all these components on the top hat that separates the source chamber containing the oven from the collision chamber.

The electron beam has an energy resolution of about $0.8 \mathrm{FWHM}$ and is pulsed at a rate of $8 \mathrm{kHz}$ with a $1.0 \mu \mathrm{s}$ pulse width. Positively charged fragments are extracted into the mass spectrometer $0.8 \mu$ s after the electron pulse. A delay generator (Stanford Research Systems DG535) is used to synchronize the pulsing of the electron gun, the ion extraction voltage, and the start of the multichannel scaler (FastComtec 7886S).

A LabVIEW program has been developed to control the data acquisition. The program steps through all electron impact energies by incrementing the electron impact energy by $0.5 \mathrm{eV}$ via a programmable power supply, reading the mass spectrum acquired by the multichannel scaler, and adding it to the data already accumulated in the appropriate place in a two-dimensional array. After each cycle through all electron impact energies, which takes about two hours, the full data set is saved. The full data set consists of a two-dimensional array of ion yield as a function of time-of-flight and as a function of electron impact energy. The data set used for extracting the ion yield curves presented in this paper consists of 14 cycles.

Several tests have been done to make sure that the ion yield curves could reliably be collected from the full data set and be normalized to the total ionization cross section. The optimization of the electron gun was done in pulsed mode by maximizing the current on the Faraday cup and ensuring that the current was independent of electron impact energy. In this way an electron beam was produced with a total current that was constant down to $15 \mathrm{eV}$ and dropping to $60 \%$ at $8 \mathrm{eV}$. Several tests have been done in which one of the voltages in the mass spectrometer was varied and the yields of the most prominent peaks in the mass spectrum were recorded. In this way voltages could be selected such that the mass spectrometer was optimized simultaneously for the detection of ions of different masses in the range $12-126 \mathrm{u}$. Two mass spectra acquired at an electron energy of $100 \mathrm{eV}$ for an equal number of electron pulses at pulse rates of $8 \mathrm{kHz}$ and $400 \mathrm{~Hz}$ were observed to be identical apart from minor statistical fluctuations. By examining mass spectra obtained after successive cycles, it has been verified that that there were no undesired effects during the collection of the data.

\section{Data analysis}

\section{1 lon yield curves}

The mass resolution of the mass spectrometer is $\Delta \mathrm{m} / \mathrm{m}=$ 0.0045 at $126 \mathrm{u}$, and above $20 \mathrm{u}$ adjacent peaks in the mass spectra are not fully separated. Ion yields have been determined by fitting adjacent peaks with sequences of normalized Gaussians. Ion yield curves have been obtained by using a LabVIEW program that fits 200 mass spectra in succession for all electron impact energies and for each group of peaks.

As the electron impact energy reached values close to the appearances energies for the peaks, problems with convergence of the fits were encountered. For this reason most fits were repeated in a region of low electron energies using a reduced number of peaks and/or a fixed value of the peak width set to the average of the fitted widths at higher energies. The data points close to threshold in the ion yield curves were obtained from these low-energy fits. In all cases it was verified that there was a region of overlap in which the low-energy fits produced close to the same values for the fitted parameters as the fits at higher electron energies.

During our experiments with thymine we have observed a gradual depletion of the intensity of the thymine beam, which was not due to the oven running empty or the capillary becoming blocked. We are not sure of the cause 
of this, but this has not been observed in experiments with the other nucleobases. A small correction factor was applied to all ion yield curves obtained from the dataset (ranging from 1 at $0 \mathrm{eV}$ to 1.0488 at $100 \mathrm{eV}$ ).

We have not been able to fully eliminate the presence of water in our vacuum system and ion yield curves of the $1 \mathrm{u}$ and 16-18 $\mathrm{u}$ fragments are not presented. We see no indication of a thymine-water dimer $(144 \mathrm{u})$ in the mass spectra, so the presence of water has had no effect on the data for thymine. The $17 \mathrm{u}$ and $18 \mathrm{u}$ ion yield curves obtained from the fitting procedure have been used for calibration of the incident electron energy by comparison with the recommended ionization cross sections for the production of $\mathrm{H}_{2} \mathrm{O}^{+}$and $\mathrm{OH}^{+}$in Itikawa and Mason (Tab. 11 in [40]) in the range $10-40 \mathrm{eV}$. The estimated error in the calibration is $\pm 0.2 \mathrm{eV}$.

\subsection{Appearance energies}

Appearance energies (onsets) have been determined by fitting an onset function convoluted with a Gaussian (see Denifl et al. [41] and references therein) to each of the ion yield curves using LabVIEW. For a single onset at $E_{0}$, the formula used is:

$$
P(E)=\int_{-\infty}^{\infty} f(\varepsilon) g(E-\varepsilon) d \varepsilon+b
$$

with

$$
\begin{aligned}
& f(\varepsilon)=0 \quad \text { if } \varepsilon \leqslant E_{0} \\
& f(\varepsilon)=c\left(\varepsilon-E_{0}\right)^{p} \quad \text { if } \varepsilon>E_{0}
\end{aligned}
$$

and

$$
g(\varepsilon)=\frac{1}{\sigma \sqrt{\pi}} \exp \left(-\varepsilon^{2} / \sigma^{2}\right)
$$

in which the electron beam width is set at $\sigma=0.8 \mathrm{eV}$, and $E_{0}, b, c$ and $p$ are the fitted parameters. In the case of two or three onsets, one or two extra terms are added to the function $f(\varepsilon)$. The convolution integral is evaluated using a 9-point Gauss-Hermite quadrature.

\subsection{Normalization of the data}

Assuming that the ion collection and detection efficiency of the mass spectrometer is mass independent, all ion yield curves extracted from the data set are on the same relative scale, and the sum of the curves can be normalized to the total ionization cross section. We have obtained two curves for the total ionization cross section as a function of electron impact energy. Figure 1 compares both curves with other experimental [42] and theoretical data [43-46].

The first curve is the sum of all the ion yield curves obtained from the fitting procedure. The normalization factor is $3.36 \times 10^{-25}$, which normalizes this curve at $70 \mathrm{eV}$ to the average of the theoretical cross sections presented in Figure 1. This normalization provides good overall agreement with the shapes of the theoretical curves in the range

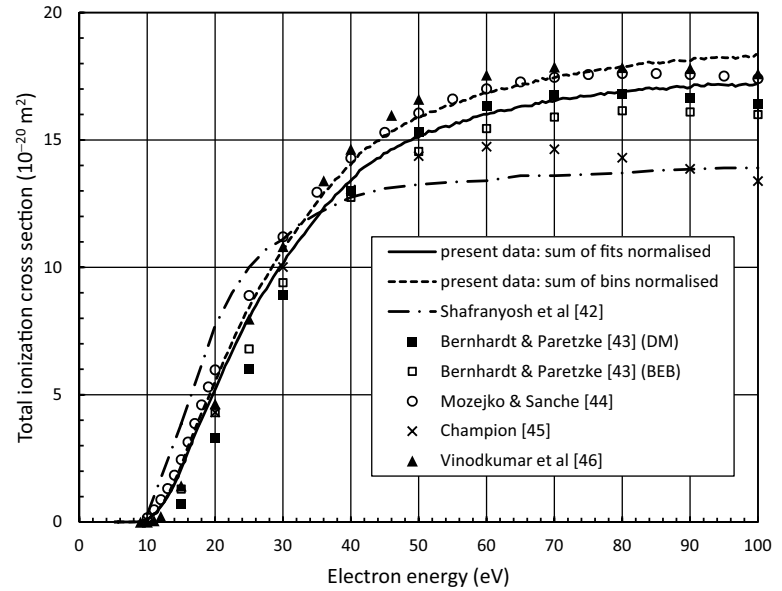

Fig. 1. Total ionization cross sections for electron impact on thymine. The lines indicate experimental results; the symbols are theoretical results. A normalization factor of $3.36 \times 10^{-25}$ has been applied to both the sum of the fits and the sum of the bins. This factor normalizes the sum of the fits at $70 \mathrm{eV}$ to the average of the theoretical cross sections in the figure.

9-100 eV. Because this curve does not include the production of the $1 \mathrm{u}$, and the 16-18 u fragments from electron impact of thymine, it slightly underestimates the total ionization cross section.

The second curve is simply the sum of all the counts collected in the mass spectra as a function of electron impact, with the exclusion of $1 \mathrm{u}, 16-18 \mathrm{u}$, and $32 \mathrm{u}$. This is a small overestimate of the total ionization cross section, because it contains background signals under and in between the thymine peaks. We have used the same normalization factor for the second curve. There is only a small difference between both curves, and the shape of the curves is in very good agreement with four of the theoretical calculations. Based on this agreement, we have applied the same normalization factor to the ion yield curves of each of the fragments to obtain partial ionization cross sections

\section{Results and discussion}

\subsection{Total ionization cross section}

Looking again at Figure 1, it is seen that there is a significant difference in the shapes of the curves total ionization cross sections obtained by us and by Shafranyosh et al. [42]. They were able to put their cross sections on an absolute scale by measuring the density of molecules in the beam by condensing their thymine beam onto a plate held at liquid nitrogen temperature. Because we have normalized our data to the theory, we cannot comment on the disagreement between the total ionization cross sections obtained by Shafranyosh et al. [42] and by the various theories. However, the shape of our curve is is in better agreement with four of the calculated cross sections than the curve of Shafranyosh et al. [42].

Five theoretical cross sections [43-46] are included in Figure 1. Calculations by Huo et al. [47] and Peudon 


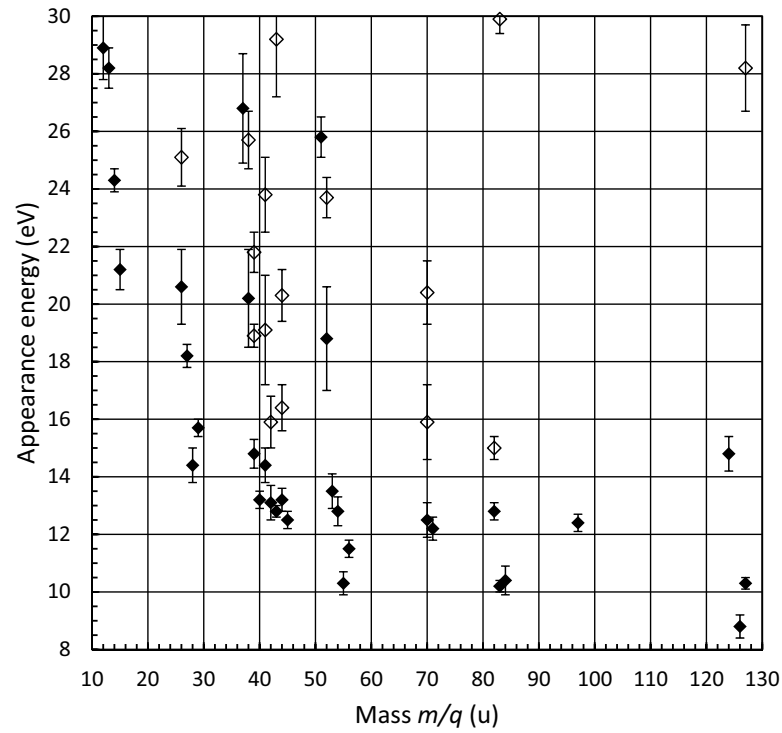

Fig. 2. Appearance energies for positive fragment ions of thymine. For each fragment, the lowest onset is shown as a solid diamond, and higher onsets are shown as open diamonds. Four onsets above $30 \mathrm{eV}$ are listed in the text.

et al. [48] are not shown in the figure; for comparisons see Figure 4 in [46]. The theoretical curves are in good agreement with each other in the range $9-100 \mathrm{eV}$. Compared to the other calculations, the curve from Champion [45] drops more rapidly above $60 \mathrm{eV}$. Champion [45] comments that the shapes of the theoretical curves from 10 to $1000 \mathrm{eV}$ are very similar, but that there are differences in the heights and the positions of the maxima.

\subsection{Appearance energies}

Figure 2 shows the appearance energies obtained for each of the thymine fragments. The errors are based on the fits only, and do not incorporate the error in the energy calibration. Four onsets above $30 \mathrm{eV}$ are not shown in the graph: $12 \mathrm{u}: 43.7 \pm 2.7 \mathrm{eV}, 25 \mathrm{u}: 32.5 \pm 1.1 \mathrm{eV}, 37 \mathrm{u}$ : $33.3 \pm 1.0 \mathrm{eV}$, and $51 \mathrm{u}: 33.4 \pm 0.7 \mathrm{eV}$. Figure 3 shows partial ionization cross sections of five selected fragments, their appearance energies, and fitted onset functions.

Our appearance energy for the parent ion, $8.8 \pm$ $0.4 \mathrm{eV}$, is in good agreement with other measurements of the ionization energies of thymine, listed in Table 4 of reference [26].

Table 1 compares the appearance energies observed for electron impact in the present work with those obtained for photon impact by Jochims et al. [26]. Whereas some of the appearance energies are in reasonable or good agreement, others are clearly different. Several of our ion yield curves rise very rapidly just above threshold, requiring high values of $p$ in the fits (e.g. $p=1.71 \pm 0.11$ for $126 \mathrm{u}$, $p=1.9 \pm 0.2$ for $83 \mathrm{u}$ and $p=3.0 \pm 0.4$ for $55 \mathrm{u}$ ). The best values of the fitted parameters and their estimated errors are therefore based on the selections of data points above threshold that are included in the fits.
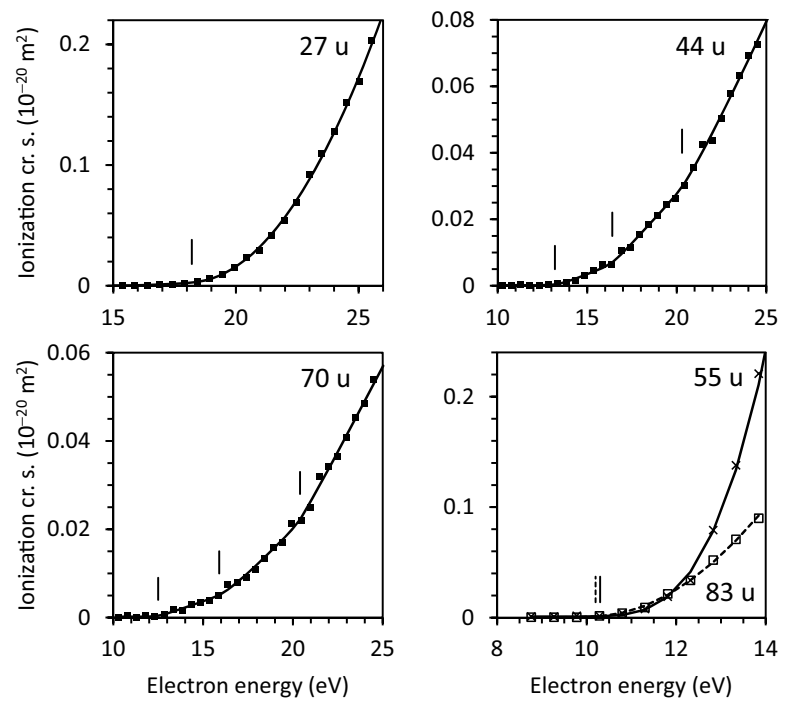

Fig. 3. Partial ionization cross sections of five selected thymine fragments. The appearance energies, second and third onsets, and fitted onset functions are also shown. $55 \mathrm{u}$ and $83 \mathrm{u}$ have nearly the same appearance energy.

Table 1. Comparison of appearance energies for electron impact and for photon impact.

\begin{tabular}{ccc}
\hline & Present data & Jochims et al. [26] \\
\hline $126 \mathrm{u}$ & $8.8 \pm 0.4$ & $8.82 \pm 0.03$ \\
$83 \mathrm{u}$ & $10.2 \pm 0.2$ & $10.70 \pm 0.05$ \\
$82 \mathrm{u}$ & $12.8 \pm 0.3$ & $13.20 \pm 0.05$ \\
$55 \mathrm{u}$ & $10.3 \pm 0.4$ & $11.7 \pm 0.1$ \\
$54 \mathrm{u}$ & $12.8 \pm 0.5$ & $\approx 12.9$ \\
$43 \mathrm{u}$ & $12.8 \pm 0.2$ & $11.9 \pm 0.1$ \\
$39 \mathrm{u}$ & $14.8 \pm 0.5$ & $14.4 \pm 0.1$ \\
$28 \mathrm{u}$ & $14.4 \pm 0.6$ & $13.6 \pm 0.1$ \\
\hline
\end{tabular}

Notably the appearance energies for the $83 \mathrm{u}$ and $55 \mathrm{u}$ fragments are lower than those reported by Jochims et al. [26]. Figure 3 (bottom-right) shows the ion yield curves for both fragments in the $4 \mathrm{eV}$ region above threshold. Between 10.8 and $12.3 \mathrm{eV}$ the ion yields for both fragments have very similar values. In previous work $([6,8,26])$ it is generally considered that the $83 \mathrm{u}$ and $55 \mathrm{u}$ fragments are resulting from a successive loss of HNCO and $\mathrm{CO}$ from the parent ion. However, the nearly equal onsets observed in the present work strongly suggest that near threshold the $55 \mathrm{u}$ ion is formed directly by the breakage of two bonds in the ring. This will be discussed further in Section 4.3.5.

The higher appearance energies observed for $82 \mathrm{u}$ compared to $83 \mathrm{u}$, and for $54 \mathrm{u}$ compared to $55 \mathrm{u}$, are both consistent with the loss of an additional hydrogen atom. Other sequences of progressively higher onsets indicate the formation of smaller fragments by successive loss of hydrogen atoms: 53-52-51 u, 40-39-38-37 u, 28-27-26 u and 15-14-13 u.

In several of the ion yield curves we observe second and (occasionally) third onsets. This is not unexpected for the smaller fragments, because multiple fragmentations may be possible for the formation of these, but it is difficult to draw specific conclusions with regard to possible 
<smiles>Cc1c[nH]c(=O)[nH]c1=O</smiles>

(a)

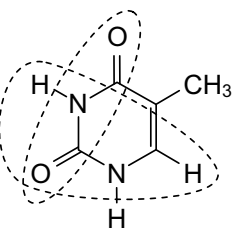

(d)

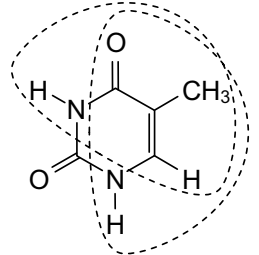

(b)

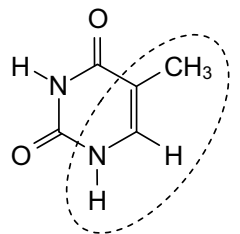

(e)

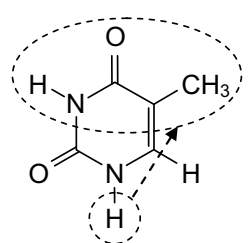

(c)

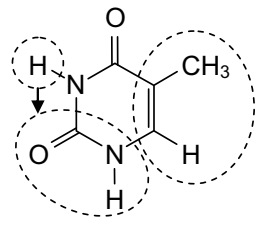

(f)
Fig. 4. (a) Structure of the thymine molecule, (b)-(e) possible dissociation processes of the core-ionized thymine molecule. The encircled regions show possible assignments of the observed positive ions (see text for more details): (b) $83 \mathrm{u}$, (c) $71 \mathrm{u}$, (d) $70 \mathrm{u}$, (e) $55 \mathrm{u}$, and (f) $44 \mathrm{u}$ (left) and $40 \mathrm{u}$ (right).

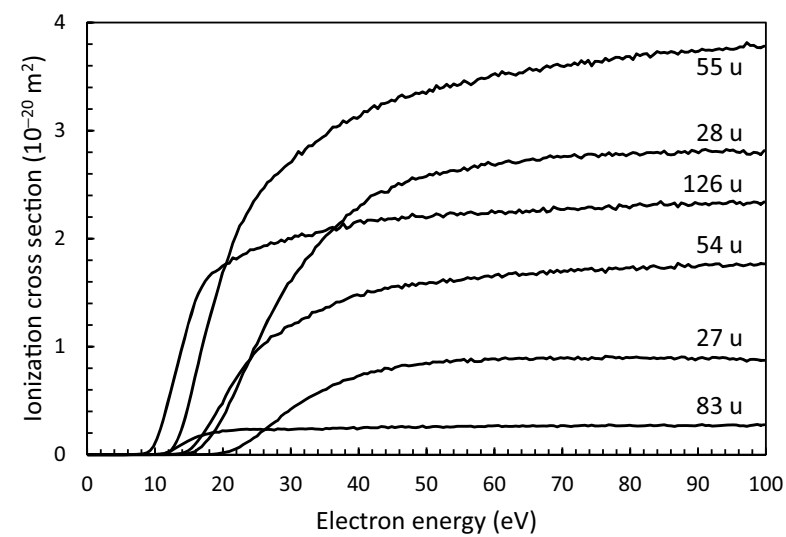

Fig. 5. Partial ionization cross sections of the 5 most abundant fragments of thymine. Because of its low appearance energy, the partial ionization cross section of $83 \mathrm{u}$ is also shown.

fragmentation processes. Contrary to cytosine [49], the 13-15 u fragments of thymine do not show second onsets, but the ion yield curves of these fragments have poor statistics.

\subsection{Partial ionization cross sections and fragmentation processes}

In the following paragraphs we consider possible fragmentation processes based on the data we have obtained, and on the results of earlier research. We have grouped the peaks such that the group number is the number of $\mathrm{C}, \mathrm{N}$, and $\mathrm{O}$ atoms in the fragment. Prominent fragmentations are illustrated in Figure 4, which also shows the structure of the thymine molecule. Lists of possible configurations of each of the fragment ions can be found in Table 3 of Jochims et al. [26] and Table 4 of Tabet et al. [33].

Ion yield curves for the five most abundant fragments are presented in Figure 5. For comparison the ion yield

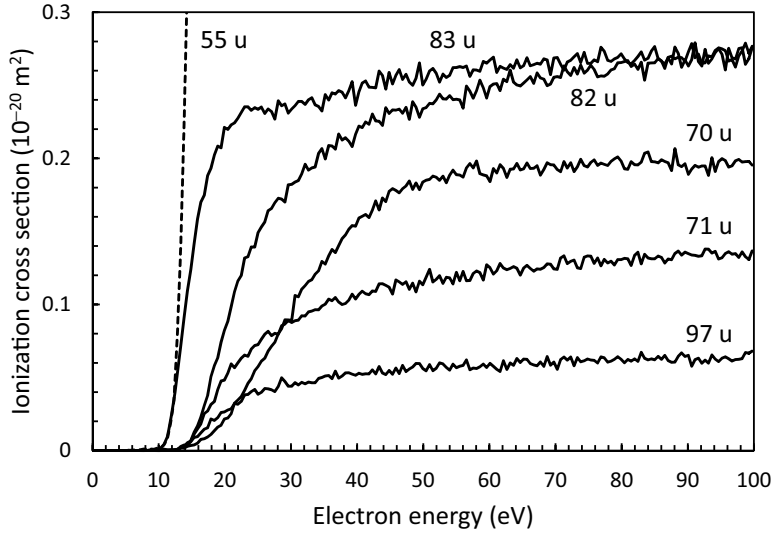

Fig. 6. Partial ionization cross sections of the $97 \mathrm{u}, 83 \mathrm{u}$, $82 \mathrm{u}, 71 \mathrm{u}$ and $70 \mathrm{u}$ fragments of thymine. Part of the partial ionization cross section of $55 \mathrm{u}$ (dashed line) is also shown for comparison.

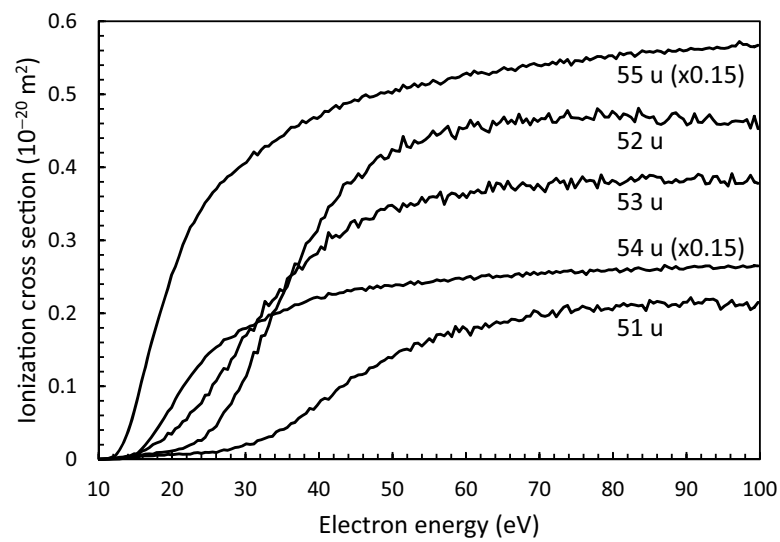

Fig. 7. Partial ionization cross sections of the $51-55 \mathrm{u}$ fragments of thymine.

curve of $83 \mathrm{u}$ is also shown. Most of the other ion yield curves are presented in Figures 6-8, and will be discussed below. A full set of ion yield curves can be obtained from the authors.

Thymine can occur in different tautomeric forms (see e.g. [50-52]), but spectroscopic studies show that at the temperature used in our oven only one tautomer is present (see discussion in Ref. [26]). Measurements of electron ionization of cytosine [49] have shown that several groups of fragments have ion yield curves with nearly the same shape, pointing to the relevance of tautomerization in the fragmentation of cytosine, but we do not see such similarities in the ion yield curves of thymine. However, the formation of the $71 \mathrm{u}$ fragment likely involves a bond rearrangement with a hydrogen atom (see discussion below).

\subsubsection{Group $9(124,126,127$ u)}

As discussed above, $126 \mathrm{u}$ has an appearance energy of $8.8 \pm 0.4 \mathrm{eV}$, in good agreement with other research (see Tab. 4 in [26]). This is the lowest onset observed. 


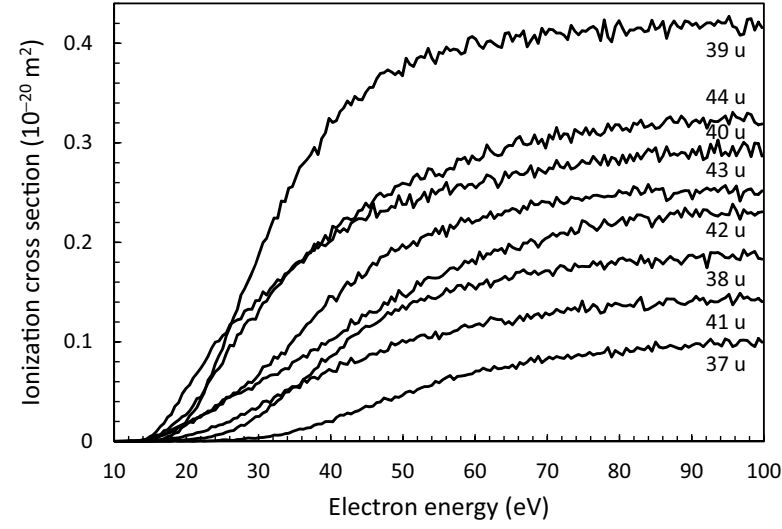

Fig. 8. Partial ionization cross sections of the $37-44 \mathrm{u}$ fragments of thymine.

The presence of $127 \mathrm{u}(10 \%$ of $126 \mathrm{u}$ at $100 \mathrm{eV})$ could be due to an isotope contribution and/or protonated thymine. Protonated thymine could possibly be the formed in the decay of thymine dimmers, which would explain the somewhat higher appearance energy of $127 \mathrm{u}$, but we do not see any indication of fragments in the range 128-166 u (we did not extend our time-of-flight range to higher masses). Because the $127 \mathrm{u}$ peak is weak and in the tail of the very prominent $126 \mathrm{u}$ peak, the fitted area of this peak may be less reliable, and the $127 \mathrm{u}$ ion yield curve is not shown in this paper.

Given that $55 \mathrm{u}$ and $28 \mathrm{u}$ are the most prominent fragments of thymine, $56 \mathrm{u}$ and $29 \mathrm{u}$ could mostly be due to the fragmentation of $127 \mathrm{u}$. Similar to $83 \mathrm{u}$ and $55 \mathrm{u}$, the ion yield curves of $84 \mathrm{u}$ and $56 \mathrm{u}$ have very low appearance energies. $45 \mathrm{u}$ may also be a fragment of $127 \mathrm{u}$. We will not discuss these fragments in the remained of this paper, but the appearance energies for these fragments are included in Figure 2.

There is a very weak peak at $124 \mathrm{u}$, with an appearance energy which is consistent with the loss of two hydrogen atoms. No other peaks are observed in this group. This is in contrast to dissociative electron attachment, in which various fragmentations leading to $124 \mathrm{u}$ and $125 \mathrm{u}$ negative ions have been observed [13-16].

\subsubsection{Group 7 (97 u)}

We observe the weak presence of $97 \mathrm{u}$ in our mass spectra. This fragment is not discussed in references [6,8], although it is present in the $70 \mathrm{eV}$ mass spectrum in reference [6]. The mass spectrum of ${ }^{14} \mathrm{C} 2$-thymine [7] shows this fragment at $99 \mathrm{u}$, indicating that it contains the $\mathrm{C} 2$ atom. Jochims et al. [26] suggest that this fragment is possibly $\mathrm{C}_{4} \mathrm{H}_{3} \mathrm{NO}_{2}^{+}$, resulting from the loss of $\mathrm{NH}_{2} \mathrm{CH}$, i.e. the simultaneous loss of the $\mathrm{HCNH}$ group and a single hydrogen atom. Another possibility is the simultaneous loss of the CO group containing the $\mathrm{C} 4$ atom and a single hydrogen atom. Denifl et al. [14] identify this as the configuration of $97 \mathrm{u}$ observed in dissociative electron attachment. The ion yield curve of $97 \mathrm{u}$ is shown in Figure 6. A number of smaller fragments $(54 \mathrm{u}, 55 \mathrm{u}, 71 \mathrm{u}, 83 \mathrm{u}$ ) have lower appearance energies than $97 \mathrm{u}$, which shows that these fragments are not produced by further fragmentation of $97 \mathrm{u}$.

\subsubsection{Group 6 (82, 83 u)}

Various authors have identified the loss of $\mathrm{HNCO}$ as the pathway leading to the $83 \mathrm{u}$ fragment. There are three possible configurations for the resulting $83 \mathrm{u}$ fragment, but calculations by Improta et al. [25] of possible minimum energy structures and relative stabilities of $\mathrm{C}_{4} \mathrm{H}_{5} \mathrm{NO}^{+}$isomers indicate that the $\left[\mathrm{OC}-\mathrm{C}_{3} \mathrm{H}_{4}-\mathrm{NH}\right]^{+}$structure resulting from the $\mathrm{N} 1-\mathrm{C} 2$ and $\mathrm{N} 3-\mathrm{C} 4$ bond breaks is the most likely.

Imhoff et al. [8] have observed the $83 \mathrm{u}$ fragment to shift to $87 \mathrm{u}$ in the case of electron impact fragmentation of thymine- $\mathrm{d}_{3}-6$ - $\mathrm{d}$, but this does not rule out any of the three possible configurations (this does rule out simultaneous $\mathrm{HNCH}+\mathrm{CH}_{3}$ loss). However, the mass spectrum of ${ }^{14} \mathrm{C} 2-$ thymine [7] shows no shifts of the $82 \mathrm{u}$ and $83 \mathrm{u}$ peaks, so the structure resulting from the $\mathrm{C} 2-\mathrm{N} 3$ and $\mathrm{C} 4-\mathrm{C} 5$ bonds is ruled out. The possible fragment ion configurations are shown in Figure $4 \mathrm{~b}$.

The $82 \mathrm{u}$ fragment could be produced by $\mathrm{H}$ loss from $83 \mathrm{u}$, consistent with the higher onsets observed in [26] and in the present work, see Table 1 . The loss of the $\mathrm{CH}_{3}$ or the $\mathrm{NH}$ group from $97 \mathrm{u}$ (if formed by $\mathrm{CO}$ and $\mathrm{H}$ loss) is ruled out by the fact that the $82 \mathrm{u}$ peak does not shift in the mass spectrum of ${ }^{14} \mathrm{C} 2$-thymine. The ion yield curves for these fragments are shown in Figure 6. At higher electron energies the formations of $82 \mathrm{u}$ and $83 \mathrm{u}$ become equally likely.

\subsubsection{Group 5 (70, $71 \mathrm{u})$}

$70 \mathrm{u}$ and $71 \mathrm{u}$ are clearly present in our mass spectra. At higher electron energies, the formation of $70 \mathrm{u}$ is more likely than $71 \mathrm{u}$ (see Fig. 6). The ion yield curve of $70 \mathrm{u}$ shows three onsets (Fig. 3, bottom left), whereas only one onset has been identified for $71 \mathrm{u}$.

$70 \mathrm{u}$ and $71 \mathrm{u}$ are also visible in the mass spectra in references [6-8], and are reported in reference [26]. The peaks shift to $71 \mathrm{u}$ and $72 \mathrm{u}$ in the mass spectrum of ${ }^{14} \mathrm{C} 2$-thymine [7], which indicates that the $70 \mathrm{u}$ fragment contains the $\mathrm{C} 2$ atom, whereas the $71 \mathrm{u}$ fragment does not. We consider four possible combinations of two bond breaks in the ring, each resulting in a fragment with $5 \mathrm{C}$, $\mathrm{N}$, and $\mathrm{O}$ atoms.

Breakage of the N1-C6 and N3-C4 bonds would result in $\mathrm{C}_{4} \mathrm{H}_{4} \mathrm{O}^{+}(68 \mathrm{u})$ with the loss of $\mathrm{CH}_{2} \mathrm{~N}_{2} \mathrm{O}(58 \mathrm{u})$, but $68 \mathrm{u}$ and also $58 \mathrm{u}$ are absent in our mass spectra, so pathways producing stable ionized fragments of either of these masses do not exist. In contrast to this, $68 \mathrm{u}$ has been observed in DEA [14].

Breakage of the N1-C2 and C4-C5 bonds would lead to $\mathrm{OCNHCO}^{+}(71 \mathrm{u}$, containing the $\mathrm{C} 2$ atom), with the loss of $\mathrm{C}_{3} \mathrm{H}_{5} \mathrm{~N}(55 \mathrm{u})$. Loss of an additional hydrogen atom 
could lead to $\mathrm{OCNCO}^{+}$, which is a possible pathway for the formation of $70 \mathrm{u}$. This pathway has been suggested by Ulrich et al. [7].

Breakage of the N3-C4 and C5-C6 bonds would lead to $\mathrm{C}_{2} \mathrm{H}_{3} \mathrm{~N}_{2} \mathrm{O}^{+}(71 \mathrm{u}$, also containing the $\mathrm{C} 2$ atom $)$, with the loss of $\mathrm{C}_{3} \mathrm{H}_{3} \mathrm{O}(55 \mathrm{u})$. Loss of an additional hydrogen atom (from 3 possible locations) would yield $\mathrm{C}_{2} \mathrm{H}_{2} \mathrm{~N}_{2} \mathrm{O}^{+}$which is another possible pathway for the formation of $70 \mathrm{u}$. Both these fragmentations are illustrated in Figure $4 \mathrm{~d}$. This pathway, followed by a N3-C6 bond formation, leading to a structure of the 1,2,5-oxadiazole cation, has been suggested by Jochims et al. [26].

Both pathways just discussed are ruled out for $71 \mathrm{u}$, because the $71 \mathrm{u}$ fragment does not contain the $\mathrm{C} 2$ atom. Jochims et al. [26] incorrectly assign $71 \mathrm{u}$ to $\mathrm{OCNHCO}^{+}$. Denifl et al. [14] in DEA assign $71 \mathrm{u}$ to $\mathrm{C}_{2} \mathrm{H}_{3} \mathrm{~N}_{2} \mathrm{O}^{-}$, which is still a possibility if DEA follows different fragmentation pathways.

The only possibility left is that the $71 \mathrm{u}$ positive ion is formed by breakage of the $\mathrm{C} 2-\mathrm{N} 3$ and C5-C6 bonds, followed by a bond rearrangement where one hydrogen atoms from the other fragment attaches to the C5 atom, resulting in $\mathrm{C}_{3} \mathrm{H}_{4} \mathrm{NO}^{+}$. This is illustrated in Figure $4 \mathrm{c}$. The slightly higher appearance energy of $70 \mathrm{u}$ could be consistent with this.

\subsubsection{Group 4 (51-56 u)}

In this group we observe clear peaks from $51 \mathrm{u}$ to $56 \mathrm{u}$. The partial ionization cross sections for 51-55 u have very different shapes (Fig. 7). At electron energies above $20 \mathrm{eV}$ the $55 \mathrm{u}$ fragment has the highest yield in the mass spectrum. Purely based on the geometry of the parent molecule, several configurations could be proposed for the $55 \mathrm{u}$ ion, however, based on the observed shift of the $55 \mathrm{u}$ peak to $59 \mathrm{u}$ in the mass spectrum of thymine- $\mathrm{d}_{3}-6-\mathrm{d}$, Imhoff et al. [8] assign $55 \mathrm{u}$ to $\mathrm{HNC}_{3} \mathrm{H}_{4}^{+}$. This is consistent with the mass spectrum of ${ }^{14} \mathrm{C} 2$-thymine [7], which has $55 \mathrm{u}$ as the highest peak in this group, indicating that this ion does not contain the $\mathrm{C} 2$ atom.

In previous work $[6,8,26]$ it is generally considered that the $83 \mathrm{u}$ and $55 \mathrm{u}$ fragments are resulting from a successive loss of HNCO (N1-C2 and N3-C4 bond breaks) and $\mathrm{CO}$ (C4-C5 bond break) from the parent ion. However, the essentially equal onsets observed in the present work strongly suggest that near threshold the $55 \mathrm{u}$ ion is formed directly by the breakage of the N1-C2 and C4-C5 bonds. This is illustrated in Figure 4e. This does not exclude the possibility of a successive loss of $\mathrm{HNCO}$ and $\mathrm{CO}$ at higher electron impact energies.

The $54 \mathrm{u}$ ion has the second-highest yield in this group. The higher onset for $54 \mathrm{u}$ is consistent with the loss of a hydrogen atom from $55 \mathrm{u}$. For thymine- $\mathrm{d}_{3}-6-\mathrm{d}$, Imhoff et al. [8] observe two peaks at $57 \mathrm{u}$ and $58 \mathrm{u}$, also consistent with the loss of a single $\mathrm{H}$ or $\mathrm{D}$ atom. The appearance energies of $82 \mathrm{u}$ and $54 \mathrm{u}$ obtained in this work are equal, which implies that near threshold $54 \mathrm{u}$ is not formed by CO loss from $82 \mathrm{u}$. However, combined $\mathrm{CO}$ and $\mathrm{H}$ loss from $83 \mathrm{u}$ would still be a possibility. $54 \mathrm{u}$ has also been observed in DEA [14].

For the remaining peaks it is difficult to draw any conclusions from our measurements. The higher onsets of $52 \mathrm{u}$ and $51 \mathrm{u}$ are consistent with loss of one or more hydrogen atoms from the higher masses. It is not possible to provide definitive assignments for the 51-53 u fragments.

\subsubsection{Group 3 (37-44 u)}

The progressively increasing onsets for $40 \mathrm{u}, 39 \mathrm{u}, 38 \mathrm{u}$, and $37 \mathrm{u}$ are consistent with the loss of one or more hydrogen atoms. The relative intensities of these peaks do not change much in the spectrum of ${ }^{14} \mathrm{C} 2$-thymine [7] indicating that these fragments do not contain the $\mathrm{C} 2$ atom. However, the peaks in this group shift to higher mass in the mass spectrum of thymine- $\mathrm{d}_{3}-6-\mathrm{d}$ [8], indicating that these fragments contain one or more $\mathrm{D}$ atoms. This excludes the assignment of $40 \mathrm{u}$ to either $\mathrm{C}_{2} \mathrm{H}_{2} \mathrm{~N}^{+}$or $\mathrm{C}_{2} \mathrm{O}^{+}$.

As in previous work [8], $40 \mathrm{u}$ is assigned to $\mathrm{C}_{3} \mathrm{H}_{4}^{+}$, illustrated in Figure 4f, with $39 \mathrm{u}, 38 \mathrm{u}$, and $37 \mathrm{u}$ formed by loss of one or more hydrogen atoms. The ion yield curves show that above $26 \mathrm{eV} 39 \mathrm{u}$ has the highest yield in this group. $40 \mathrm{u}$ has an appearance energy that is $2.9 \mathrm{eV}$ higher than that of $55 \mathrm{u}$, so this ion could be formed by HN loss from $\mathrm{HNC}_{3} \mathrm{H}_{4}^{+}$. Imhoff et al. [8] suggest that the peak at $40 \mathrm{u}$ may be partly due to $\mathrm{NCN}^{+}$, but this is contradicted by the mass spectrum of ${ }^{14} \mathrm{C} 2$-thymine [7] which indicates that $40 \mathrm{u}$ does not contain the $\mathrm{C} 2$ atom.

Looking at the 41-44 u peaks, there seem to be some shifts to higher mass in the mass spectra of ${ }^{14} \mathrm{C} 2$-thymine [7] and thymine- $\mathrm{d}_{3}-6-\mathrm{d}$ [8]. We observe nearly the same appearance energies for $40 \mathrm{u}, 42 \mathrm{u}, 43 \mathrm{u}$, and $44 \mathrm{u}(12.8-13.2 \mathrm{eV})$, whereas the appearance energy of $41 \mathrm{u}$ is about $1.4 \mathrm{eV}$ higher. The ion yield curves in this group are quite similar, and $44 \mathrm{u}$ has the highest yield (see Fig. 8). This indicates that there may be different fragmentation processes leading to $42 \mathrm{u}, 43 \mathrm{u}$, and $44 \mathrm{u}$, but that the weak peak at $41 \mathrm{u}$ is due to hydrogen loss from $42 \mathrm{u}$.

In the absence of any bond rearrangements and loss of individual hydrogen atoms, the only possible assignment of $43 \mathrm{u}$ is to $\mathrm{HNCO}^{+}([6,8,26])$. There are three possible combinations of breakage of two bonds in the ring that could lead to this configuration. The appearance energy of $43 \mathrm{u}$ shows that this fragment could be formed by successive fragmentation via bigger fragments $(83 \mathrm{u}, 71 \mathrm{u}$, $70 \mathrm{u}) .43 \mathrm{u}$ is also a prominent fragment in soft X-ray induced fragmentation of thymine [27].

Imhoff et al. [8] have suggested that $44 \mathrm{u}$ may be assigned to $\mathrm{CH}_{2} \mathrm{NO}^{+}$formed by the oxygen atom in the $\mathrm{HNCO}^{+}$fragment abstracting a hydrogen atom from either the $\mathrm{CH}_{3}$ group or the NH group. This is illustrated in Figure $4 \mathrm{f}$.

$42 \mathrm{u}$ has a slightly higher appearance energy than $43 \mathrm{u}$, indicating that this fragment could be formed by hydrogen loss from $43 \mathrm{u}$. Another possibility is $\mathrm{CNO}^{+}$formed by loss of $\mathrm{CO}$ from $\mathrm{OCNCO}^{+}(70 \mathrm{u})$. An unlikely possibility is $\mathrm{CH}_{2} \mathrm{~N}_{2}^{+}$formed by the breaking of two diagonal bonds 
in the parent molecule producing $\mathrm{CH}_{2} \mathrm{~N}_{2} \mathrm{O}^{+}(58 \mathrm{u}$, not observed), followed by the loss of the $\mathrm{O}$ atom producing $\mathrm{CH}_{2} \mathrm{~N}_{2}^{+}$Loss of a hydrogen atom would then produce $\mathrm{CHN}_{2}^{+}(41 \mathrm{u}) .42 \mathrm{u}$ has also been observed in DEA [14].

\section{Conclusion}

Although selective bond breaking by electron impact leading to positive fragments is not as clearly visible as in dissociative electron attachment (DEA), the comparison of the mass spectra of thymine, ${ }^{14} \mathrm{C} 2$-thymine [7] and thymine-methyl- $\mathrm{d}_{3}-6-\mathrm{d}[8]$ rules out a number of possible fragmentations, allows the identification of the structure of some fragments, and clearly shows that also in the production of positively charged fragments selective dissociation pathways are preferred.

The appearance energies determined in the present work reduce the number of possible successive fragmentations leading to smaller fragments. The appearance energies are in a number of cases consistent with the loss of one or more hydrogen atoms from a heavier fragment (83-82 u, 55-54 u, 53-52-51 u, 40-39-38-37 u, 28-27-26 u and 15-14-13 u).

In previous papers it has been suggested that the $83 \mathrm{u}$ and $55 \mathrm{u}$ fragments are resulting from a successive loss of $\mathrm{HNCO}$ and $\mathrm{CO}$ from the parent ion. However, the nearly equal appearance energies of these fragments observed in the present work strongly indicate that near threshold the $55 \mathrm{u}$ ion is formed directly by the breakage of two bonds in the ring, and that $83 \mathrm{u}$ and $55 \mathrm{u}$ may be formed via different fragmentation pathways. The equal appearance energies of $82 \mathrm{u}$ and $54 \mathrm{u}$ indicate that near threshold $54 \mathrm{u}$ is not formed by CO loss from $82 \mathrm{u}$.

The mass spectrum of ${ }^{14} \mathrm{C} 2$-thymine [7] indicates that the $70 \mathrm{u}$ fragment contains the $\mathrm{C} 2$ atom, whereas the $71 \mathrm{u}$ fragment does not. This restricts the possible configurations of both fragments, shows that $70 \mathrm{u}$ is not formed by hydrogen loss from $71 \mathrm{u}$, and implies that 71 must be formed via a double bond break in the ring, followed by a bond rearrangement with a hydrogen atom, possibly related to tautomerization in the fragmentation.

The authors gratefully acknowledge financial support for scientific visits received from the Nano-IBCT project (COST Action MP1002) and the ITS-LEIF project (FP6 Grant No. RII3-026015), both funded by the European Union. Part of the equipment used in this experiment was funded by Enterprise Ireland. The authors also wish to acknowledge Mr. David Watson for his contributions to the mechanical design of the apparatus and to Mr. Pat Seery for his contributions to the electronics equipment.

\section{References}

1. H. Hotop, M.-W. Ruf, M. Allan, I.I. Fabrikant, Adv. At. Mol. Opt. 49, 85 (2003)

2. R. Balog, J. Langer, S. Gohlke, M. Stano, H. AbdoulCarime, E. Illenberger, Int. J. Mass. Spectrom. 233, 267 (2004)
3. L. Sanche, Eur. Phys. J. D 35, 367 (2005)

4. J.W. McConkey, C.P. Malone, P.V. Johnson, C. Winstead, V. McKoy, I. Kanik, Phys. Rep. 466, 1 (2008)

5. I. Baccarelli, I. Bald, F.A. Gianturco, E. Illenberger, J. Kopyra, Phys. Rep. 508, 1 (2011)

6. J.M. Rice, G.O. Dudek, M. Barber, J. Am. Chem. Soc. 87, 4569 (1965)

7. J. Ulrich, R. Teoule, R. Massot, A. Cornu, Org. Mass Spectrom. 2, 1183 (1969)

8. M. Imhoff, Z. Deng, M.A. Huels, Int. J. Mass Spectrom. 245, 68 (2005)

9. R. Abouaf, J. Pommier, H. Dunet, Chem. Phys. Lett. 381, $486(2003)$

10. C. Dal Cappello, I. Charpentier, S. Houamer, P.A. Hervieux, M.F. Ruiz-Lopez, A. Mansouri, A.C. Roy, J. Phys. B 45, 175205 (2012)

11. C. Dal Cappello, Z. Rezkallah, S. Houamer, I. Charpentier, A.C. Roy, P.A. Hervieux, M.F. Ruiz-Lopez, Eur. Phys. J. D 67, 117 (2013)

12. M.A. Huels, I. Hahndorf, E. Illenberger, L. Sanche J. Chem. Phys. 108, 1309 (1998)

13. S. Denifl, S. Ptasińska, M. Cingel, S. Matejcik, P. Scheier, T.D. Märk, Chem. Phys. Lett. 377, 47 (2003)

14. S. Denifl, S. Ptasińska, M. Probst, J. Hrušák, P. Scheier, T.D. Märk, J. Phys. Chem. A 108, 6562 (2004)

15. R. Abouaf, H. Dunet, Eur. Phys. J. D 35, 405 (2005)

16. H. Abdoul-Carime, S. Gohlke, E. Illenberger, Phys. Rev. Lett. 92, 168103 (2004)

17. S. Ptasińska, S. Denifl, V. Grill, T.D. Märk, P. Scheier, S. Gohlke, M.A. Huels, E. Illenberger, Angew. Chem. Int. Ed. 44, 1647 (2005)

18. S. Ptasińska, S. Denifl, P.L. Scheier, E. Illenberger, T.D. Märk, Angew. Chem. Int. Ed. 44, 6941 (2005)

19. S. Ptasińska, S. Denifl, B. Mróz, M. Probst, V. Grill, E. Illenberger, P. Scheier, T.D. Märk, J. Chem. Phys. 123, $124302(2005)$

20. F. Ferreira da Silva, C. Matias, D. Almeida, G. García, O. Ingólfsson, H.D. Flosadóttir, B. Ómarsson, S. Ptasinska, B. Puschnigg, P. Scheier, P. Limão-Vieira, S. Denifl, J. Am. Soc. Mass Spectrom. 24, 1787 (2013)

21. D. Almeida, D. Kinzel, F. Ferreira da Silva, B. Puschnigg, D. Gschliesser, P. Scheier, S. Denifl, G. García, L. González, P. Limão-Vieira, Phys. Chem. Chem. Phys. 15, 11431 (2013)

22. P.D. Burrow, G.A. Gallup, A.M. Scheer, S. Denifl, S. Ptasinska, T. Märk, P. Scheier, J. Chem. Phys. 124, 124310 (2006)

23. X. Li, M.D. Sevilla, L. Sanche, J. Phys. Chem. B 108, 19013 (2004)

24. A. Dora, L. Bryjko, T. van Mourik, J. Tennyson, J. Phys. B 45, 175203 (2012)

25. R. Improta, G. Scalmani, V. Barone, Int. J. Mass Spectrom. 201, 321 (2000)

26. H.-W. Jochims, M. Schwell, H. Baumgärtel, S. Leach, Chem. Phys. 314, 263 (2005)

27. E. Itälä, D.T. Ha, K. Kooser, E. Rachlew, M.A. Huels, E. Kukk, J. Chem. Phys. 133, 154316 (2010)

28. J. de Vries, R. Hoekstra, R. Morgenstern, T. Schlathölter, Eur. Phys. J. D 24, 161 (2003)

29. J. de Vries, R. Hoekstra, R. Morgenstern, T. Schlathölter, Phys. Rev. Lett. 91, 053401 (2003)

30. J. de Vries, R. Hoekstra, R. Morgenstern, T. Schlathölter, Phys. Scr. T110, 336 (2004) 
31. T. Schlathölter, R. Hoekstra, R. Morgenstern, Int. J. Mass Spectrom. 233, 173 (2004)

32. T. Schlathölter, F. Alvarado, R. Hoekstra, Nucl. Instrum. Methods Phys. Res. B 233, 62 (2005)

33. J. Tabet, S. Eden, S. Feil, H. Abdoul-Carime, B. Farizon, M. Farizon, S. Ouaskit, T.D. Märk, Int. J. Mass Spectrom. 292, $53(2010)$

34. S.K. Kim, W. Lee, D.R. Herschbach, J. Phys. Chem. 100, 7933 (1996)

35. N.J. Kim, H. Kang, G. Jeong, Y.S. Kim, K.T. Lee, S.K. Kim, J. Chem. Phys. 115, 15 (2001)

36. T. Kagawa, K. Aikawa, F. Sato, Y. Kato, T. Iida, Radiat. Prot. Dosim. 122, 95 (2006)

37. T. Schlathölter, F. Alvarado, S. Bari, A. Lecointre, R. Hoekstra, V. Bernigaud, B. Manil, J. Rangama, B. Huber, ChemPhysChem 7, 2339 (2006)

38. F. Zappa, S. Denifl, I. Mähr, J. Lecointre, F. Rondino, O. Echt, T.D. Märk, P. Scheier, Eur. Phys. J. D 43, 117 (2007)

39. G. Barrett, P.J.M. van der Burgt, J. Phys.: Conf. Ser. 101, 012008 (2008)

40. Y. Itikawa, N. Mason, J. Phys. Chem. Ref. Data 34, 1 (2005)
41. S. Denifl, B. Sonnweber, G. Hanel, P. Scheier, T.D. Märk, Int. J. Mass Spectrom. 238, 47 (2004)

42. I.I. Shafranyosh, M.I. Sukhoviya, M.I. Shafranyosh, L.L. Shimon, Tech. Phys. 53, 1536 (2008)

43. Ph. Bernhardt, H.G. Paretzke, Int. J. Mass Spectrom. 223-224, 599 (2003)

44. P. Możejko, L. Sanche, Radiat. Environ. Biophys. 42, 201 (2003)

45. C. Champion, J. Chem. Phys. 138, 184306 (2013)

46. M. Vinodkumar, Ch. Limbachiya, M. Barot, M. Swadia, A. Barot, J. Mass Spectrom. 339-340, 16 (2013)

47. W.M. Huo, C.E. Dateo, G.D. Fletcher, NASA Technical Report NAS-06-009, 2006

48. A. Peudon, S. Edel, M. Terrissol, Radiat. Prot. Dosim. 122, $128(2006)$

49. P.J.M. van der Burgt, Eur. Phys. J. D 68, 135 (2014)

50. J.-C. Fan, Z.-C. Shang, J. Liang, X.-H. Liu, H. Jin, J. Mol. Struct. (Theochem) 939, 106 (2010)

51. A.B. Trofimov, J. Schirmer, V.B. Kobychev, A.W. Potts, D.M.P. Holland, L. Karlsson, J. Phys. B 39, 305 (2006)

52. J. González-Vázquez, L. González, E. Samoylova, T. Schultz, Phys. Chem. Chem. Phys. 11, 3927 (2009) 